\title{
CONTROL OF PLANT DISEASES BY AN ALLIUM-BASED ANTIMICROBIAL FORMULATION
}

Oluwashina Oladejo, Jafargholi Imani*

Institute of Phytopathology, Research Centre for BioSystems, Land Use and Nutrition, Justus Liebig University, D-35392 Giessen, Germany.

\section{E-mail addresses:}

Oluwashina.Oladejo@agrar.uni-giessen.de (ORCID no.: 0000-0001-5483-0091)

jafargholi.imani@agrar.uni-giessen.de (ORCID no.: 0000-0001-8265-1656)

* Corresponding author jafargholi.imani@agrar.uni-giessen.de

\begin{abstract}
The objective of this work was to determine the antimicrobial properties of an allium-based antimicrobial formulation named VEG'LYS (https://phytoauxilium.com/) on the growth of plant pathogenic microorganisms such as fungi, oomycetes, and bacteria. Two anthracnoserelated species of the fungal genus Colletotrichum, C. gloeosporioides, and C. fragariae, the oomycete Phytophthora cactorum and the bacterium Xanthomonas fragariae associated with strawberry plants and two fungi Alternaria dauci and Botrytis cinerea, associated with carrot plants were tested in vitro. In in planta experiments, A. dauci and B. cinerea were used.. VEG'LYS inhibited the growth of all plant pathogens tested. We found that both curative and preventive in planta treatments with VEG'LYS inhibited the growth of $A$. dauci and B. cinerea in carrot. Furthermore, after spraying VEG'LYS on carrot plants the expression of the Pathogenesis-related $(P R) 10$ gene correlated with the magnitude of infection both in treated and untreated plants. Additionally, it has been shown, that the field application of VEG'LYS on strawberry plants results in a reduction of bacterial and fungal pathogens of strawberry fruits stored in refrigerator. In summary, VEG'LYS is a potential resistance inducer that seems to be suitable for use in both curative and preventive treatments to reduce the diseases and rotting of fruits and vegetables caused by different plant pathogens.
\end{abstract}

Keywords: Plant extracts, VEG'LYS, antimicrobial effects, curative and preventive treatment. 


\section{INTRODUCTION}

Plants are irreplaceable food sources for humans (Bennett, 2007). Edible, medicinal and spice plants contain a large number of secondary metabolites that retard or inhibit the growth of pathogenic microorganisms such as bacteria and fungi (Burt et al., 2003). These components are called biopesticides (Kumar et al., 2021) or botanicals and have a role in the plant's innate immune response elicited by microbial pathogens and pests, and are produced ubiquitously in roots, seeds, flowers, stems, and leaves, highlighting their physiological importance (Carlos et al., 2015). The antimicrobial compounds in plant materials are commonly found in the essential oil fraction of leaves (rosemary, sage, basil, oregano, thyme, and marjoram), flowers or buds (clove), bulbs (garlic and onion), seeds (caraway, fennel, nutmeg, and parsley), rhizomes (asafoetida), fruits (pepper and cardamom), or other parts of plants (Gutierrez et al., 2008). In the context of agricultural pest management, natural plant products are best suited for use in organic food production in industrialised countries and could also play a greater role in the production and post-harvest protection of food products in developing countries (Gurjar et al., 2012). The advantages of using compounds of plant origin to control plant diseases include mostly low health and environmental hazards and low risk of resistance development by pathogens and pests (Amadioha, 2003) and less expensive, easily available (because of their natural occurrence) and depending on the concentration, they may have less detrimental effects on seed viability, plant growth and food quality (Opara and Wokocha, 2008).

Several plant species contain antimicrobial components such as flavonoids, phenolics and triterpenoids in abundant amounts that exhibit a significant protective effect on $\mathrm{H}_{2} \mathrm{O}_{2}$-mediated injury in rat adrenal medulla PC12 cells at low concentrations, and can also prevent pathogenic growth, when applied on infected crops (Dong et al., 2014). The extract of Glycyrrhiza glabra inhibits growth of some Gram-negative bacteria such as Salmonella species, Shigella species and E. coli (Shirazi et al., 2007). Extracts from Yucca schidigera also have antibacterial activity, which was attributed to the presence of saponin, a compound found to inhibit microbial growth through haemolytic activity (Hassan et al., 2010). The control of Bacterial Leaf Spot (BLS) caused by seed-borne Xanthomonads by means of biopesticides in tomato has provided an alternative control approach against copper-resistant strains present in Tanzania (Shenge et al., 2007). Moreover, plant extracts from Aloe vera, Coffea arabica and Yucca schidigera are potential candidates for seed treatment against seed-borne Xanthomonads in tomato (Mbega et al., 2012). The most commonly and sustainably used biopesticides in agricultural practice are extracts of the Neem tree (Azadirachta indica, A. juss) and garlic 
(Allium sativum, L.), essential oils from Nettle (Urtica spp.), rue (Ruta graveolens), thyme (Thymus vulgaris) and tea tree (Melaleuca alternifolia) (Gurjar et al., 2012; Srivasata et al., 2011). Especially components with phenolic structures such as caracole, eugenol, and thymol were highly active against plant pathogens (Das et al., 2010).

An Allium-based antimicrobial formulation from garlic and onion was recently tested for antimicrobial properties in several applications. The volatile antimicrobial substance allicin, a thiosulfinate with two allyl groups as carbon chains (diallylthiosulphinate), is synthesized in garlic (Leontive et al., 2018), when the tissues are damaged and the substrate alliin (S-allyl-Lcysteine sulfoxide) is converted by the enzyme alliin lyase. Allicin is readily membranepermeable and undergoes thiol-disulfide exchange reactions with free thiol groups in proteins. Allicin applications reduced seed-borne Alternaria spp on carrot, Phytophthora leaf blight on tomato and tuber blight on potato, Magnaporthe on rice and downy mildew (Peronospora parasitica) on Arabidopsis thaliana (Koch and Slusarenko 1990; Slusarenko et al., 2008). The product named VEG'LYS was developed as antimicrobial product for surface sterilization of seeds, and was reported to be an effective antimicrobial product for use on seeds of bitter gourd and globe artichoke (Samadi et al., 2015; Okubara et al., 2017). The product was also used to maintain nutrient quality and extend the shelf life of strawberries, with no effect on the taste (Samadi et al., 2017). The antimicrobial effects of VEG'LYS was demonstrated against Fusarium graminearum, the causal agent of Fusarium head blight and root rot of cereals as well as powdery mildew caused by the ascomycete fungus Blumeria graminis (Imani et al., 2013).

In this study, the antimicrobial properties of VEG'LYS were further evaluated against some of the most devastating phytopathogenic microorganisms. The effect of VEG'LYS against pathogens was analysed by in vitro assays and the amount of pathogens was determined by qPCR after VEG'LYS treatment on the experimental plants. Additionally, the role of VEG'LYS as a potential systemic resistance inducer was determined by evaluation of $P R$ gene expression upon curative and preventive VEG'LYS treatment on plants.

\section{MATERIALS AND METHODS}

The Allium extract VEG'LYS was obtained from Phytoauxilium (http://phytoauxilium.com). Strawberry (Fragaria ananassa var. Cherry) and carrot (Daucus carota ssp. sativus, var. Rotin) 
plants were investigated following inoculation by the two fungal pathogens Alternaria dauci and Botrytis cinerea. Carrot plants were grown in pots in vermiculite with a grain size of 0 - 3 $\mathrm{mm}$ in a plant growing chamber under $16 \mathrm{~h}$ light $/ 8 \mathrm{~h}$ dark intervals (light intensity approx. 160 $\mu \mathrm{mol} \mathrm{m-}-^{2} \mathrm{~s}^{1}$ ) at $24^{\circ} \mathrm{C}$ with $60 \%$ relative humidity.

In vitro assays of $V E G$ 'LYS effects on pathogen growth

Three primary growth media were used, Malt Extract Peptone Agar for Colletotrichum gloeosporioides, V-8 Juice Agar for Phytophthora cactorum and Nutrient Agar for Xanthomonas fragariae. Different concentrations of VEG'LYS-F ( $0 \%, 0.01 \%, 0.05 \%, 0.1 \%$ $(\mathrm{v} / \mathrm{v}))$ were added to the media when allowed to cool down after autoclaving. Four plates of 25 $\mathrm{ml}$ medium in $100 \mathrm{~mm}$-diameter petri dishes were prepared for each VEG'LYS concentration. The inoculation of microbes onto the respective media was done using agar blocks with the help of a sterilised cork-borer and a needle. Fungal and oomycete growth was quantified using ImageJ software (http://imagej.nih.gov/ij/). The control plate served as $100 \%$ growth area. The bacterial activity was measured by optical density $\left(\mathrm{OD}_{600}\right)$.

Inoculum preparation and in vivo pathogen assays

Alternaria dauci and Botrytis cinerea conidia were collected from two-week-old sporulation medium (sucrose, $20 \mathrm{~g}$; $\mathrm{CaCO}_{3}, 30 \mathrm{~g}$; agar, $20 \mathrm{~g}$; pH 7.4; Shahin et al., 1979) and potato dextrose agar (dextrose, 15 g; Potato Extract, 4 g; water, 1 1; agar, 15 g; pH 5.6), respectively, by pouring Tween 20 water $(0.05 \% \mathrm{v} / \mathrm{v})$ and gently scrubbing with a sterile glass rod. Conidia suspensions were filtered through a single layered, sterilized Miracloth and the remaining dislodged conidia were removed by flooding the media plates with sterilize distilled water into a $50 \mathrm{ml}$ falcon tube, centrifuged at $3500 \mathrm{rpm}$ for $10 \mathrm{~min}$. The supernatant was removed and the pellet was re-suspended in $20 \mathrm{ml}$ of sterile deionized water. Conidia solutions were adjusted to $10^{3}$ conidia $\mathrm{ml}^{-1}$ and $10^{8}$ conidia $\mathrm{ml}^{-1}$, respectively, by a hemocytometer (Fuchs Rosenthal). Conidia solutions from both pathogens were then sprayed on carrot plants (Daucus carota var. 'Rotin') with the plants incubated in white plastic boxes lined with papers and maintained under $100 \%$ relative humidity with constant illumination from white light tube (Philips TLD $36 \mathrm{~W} / 830 \mathrm{HF}$ ) in the hood. Infection was evaluated at $7 \mathrm{dpi}$. 
Experimental procedure for carrot plants and pathogenic fungi following VEG'LYS treatments

This experimental procedure involved curative and preventive methods. In the curative method, $10 \mathrm{ml}$ each of $A$. dauci and B. cinerea conidia solutions $\left(10^{3}\right.$ conidia $\mathrm{ml}^{-1}$ and $10^{8}$ conidia $\mathrm{ml}^{-1}$, respectively) was sprayed on the carrot plants followed by $10 \mathrm{ml}$ of $0.03 \%(\mathrm{v} / \mathrm{v})$ VEG'LYS exactly $48 \mathrm{~h}$ after pathogen inoculation on the plant materials and vice versa for the preventive method. Four white plastic boxes lined with papers, each containing three experimental carrot plants were maintained under $100 \%$ relative humidity by spraying the plastic boxes with sterilized water under constant illumination from white light tube (Philips TLD 36 W/830HF). The first plastic box was used as the control experimental setup sprayed with sterilize distilled water, the second plastic box contained plant samples sprayed with only pathogen conidia solutions, the third as the curative carrot samples and the fourth as preventive materials. The whole experimental setup was observed for few weeks.

\section{Treatment of strawberry fields with VEG'LYS}

The strawberry field was divided into four rows with each row containing 25 strawberry plants. Different VEG'LYS concentrations were used. The first row was sprayed with sterilized water, the second row with $0.1 \% \mathrm{v} / \mathrm{v}$, the third row with $0.2 \% \mathrm{v} / \mathrm{v}$ and the fourth row with $0.5 \% \mathrm{v} / \mathrm{v}$. The application of VEG'LYS was done twice per week for one month. Nine ripe fruits were harvested separately from each row and stored in a refrigerator in an uncovered small white box and checked daily for the presence of fungal growth.

\section{Fungal DNA quantification}

Genomic DNA was extracted from carrot callus and pure cultures of $A$. dauci and B. cinerea to test the specific primers with qPCR for the carrot ubiquitin gene (forward 5'aagcccaagaagatcaagca-3'; reverse 5'-tcaaaatgattggccatgaa-3'), A. dauci glyceraldehyde-3phosphate dehydrogenase ( $g p d$ ) gene (forward 5'-aagcttccccaagcactcacaa-3' reverse 5'ctgcgttctgcagctgtagaga-3') and B. cinerea $\beta$-tubulin gene (forward 5'-gttacttgacatgctctgccatt3'; reverse 5'-cacggctacagaaagttagtttctacaa-3'. Samples from each experimental material (uninfected carrots, curative material, preventive material and carrot plants infected with $A$. dauci or B. cinerea) were collected into $50 \mathrm{ml}$ falcon tubes and immediately frozen by liquid nitrogen which were later stored at $-80^{\circ} \mathrm{C}$ from which DNA extraction was carried out for 
fungal gene quantification using QIAGEN DNeasy plant mini kit. The DNA extraction was followed by polymerase chain reaction (PCR) for the amplification of the fungal gene of interest.

\section{RNA Extraction}

For gene expression analysis, plant sample materials were crushed into fine powder in liquid nitrogen and total RNA was extracted using the TRIzol ${ }^{\circledR}$ Reagent. The RNA samples were all treated with DNAse to remove all the traces of remaining genomic DNA. The experiment was performed in PCR tubes with a total volume of $10 \mu \mathrm{L}$. Incubation followed immediately as the DNAse was added to each sample for $30 \mathrm{~min}$ at $37^{\circ} \mathrm{C}$. Subsequently, $2 \mu \mathrm{L} 0.25 \mathrm{M}$ EDTA was added and incubated at $65^{\circ} \mathrm{C}$ for $10 \mathrm{~min}$. One $\mu \mathrm{g}$ of RNA ( $5 \mu \mathrm{L}$ from the previous preparation) was used for cDNA synthesis with Quantiscript Reverse Transcriptase (Thermo Fisher Scientific Inc., Germany) with a total volume of $20 \mu \mathrm{L}$. The quality of the cDNA synthesized was checked on an Agarose gel ( $1 \mu \mathrm{L}$ from each sample) in a PCR reaction with the carrot ubiquitin gene (forward and reverse primers).

\section{Quantitative PCR ( $P P C R)$}

$200 \mathrm{ng} / \mu \mathrm{L}$ of cDNA was used as a template for the quantitative real-time PCR in an Applied Biosystems 7500 Fast real-time thermocycler (ThermoFisher Scientific Inc., Germany). A 96well plate was used for the qPCR reaction with $20 \mu \mathrm{L}$ of the reaction mixture pipetted into each well where amplification process was performed with SYBR Green JumpStart TaqReadyMix (Sigma-Aldrich GmbH, Germany). Each sample was performed with three repetitions. Each run of the qPCR reaction included a non-template control in order to rule out test reagent contamination. Respective melting curves were determined at the end of each cycle to ensure amplification of only one PCR product. $C_{t}$ values were calculated with the 7500 Fast software supplied with the instrument. Transcript levels of the target genes were determined via the $\Delta \mathrm{Ct}$ method with a reference gene (Schmittgen and Livak, 2008). The relative expression of each pathogen genes versus the plant reference gene (carrot ubiquitin) was calculated, then the ratio of expression and the biomass of fungal DNA for each sample was determined against the control sample (Wild type Carrot plants). All statistical calculations were made via unpaired two-tailed student's t-test. 


\section{RESULTS}

VEG'LYS has strong antimicrobial effects against various microbial pathogens in in vitro assays

First, we determined the antimicrobial effects of different VEG'LYS concentrations in inhibiting the in vitro growth of microbial pathogens in axenic culture. VEG'LYS $(0.01 \%$ and $0.05 \% \mathrm{v} / \mathrm{v}$ ) completely inhibited the axenic growth of the oomycete Phytophthora cactorum (Fig. 1a,b). Moreover, $0.05 \%$ and $0.1 \%$ VEG'LYS also completely inhibited the axenic growth of the ascomycete Colletotrichum gloeosporioides, while $0.01 \%$ VEG'LYS strongly but not completely inhibited its growth (Fig. 2a,b). The growth of the bacterium Xanthomonas fragariae in liquid medium also was strongly inhibited by $0.01 \%$ and $0.02 \%$ VEG'LYS as shown by the significant lower $\mathrm{OD}_{600}$ values as compared to the untreated control (Fig. 3).

Evaluation of fungal growth and PR gene expression upon curative and preventive VEG'LYS treatments

Next, we tested the effects of VEG'LYS on the two devastating ascomycete pathogens Alternaria dauci and Botrytis cinerea during carrot plant infection. Fungal conidia $\left(10^{8}\right.$ and $10^{3}$ conidia $\mathrm{ml}^{-1}$, respectively) were sprayed in a volume of $10 \mathrm{ml}$ per plant. At 7 dpi, carrot leaves and petioles showing heavy symptoms of gray mold caused by Botrytis cinerea.. Gradual fungal growth was observed in plants inoculated with $A$. dauci conidial solutions, taking up to six weeks for total infection of all parts of the plants. In contrast, the untreated plants were strongly infected and infection symptoms were visible in virtually every part of the plants (Fig. S1). To estimate the level of infection on both VEG'LYS treated and untreated plant material, we quantified the expression of A. dauci Glyceraldehyde-3-phosphate dehydrogenase (Adgpd) and $B$. cinerea $\beta$-tubulin genes $(B c 1)$ by qPCR and normalized it with the carrot ubiquitin gene. Both preventive and curative treatments of carrot plants with VEG'LYS strongly reduced $A$. dauci and B. cinerea infections (Fig. 4; S2).

Next, we analysed the expression levels of the genes Dau c1.01, Dau c1.02 and Dau c1.03, which all belong to the $P R 10$ gene family of carrot, in treated vs. untreated samples. The carrot plants were inoculated with $A$. dauci and B. cinerea, respectively, and treated with VEG'LYS vs. mock. We found that in all the treated carrot plants the expression of $P R 10$ family genes 
were significantly reduced compared with the untreated plants (Fig. 5), corroborating that the development of the fungi is greatly reduced by VEG'LYS.

Pre-harvest VEG'LYS application on a strawberry fields prevented post-harvest pathogenic growth

To evaluate the effect of VEG'LYS in extending the shelf life of strawberry, nine fruits from each row were harvested and stored in the fridge in an uncovered small box and observed daily for the presence of fungal growth. We found that pre-harvest VEG'LYS application in a strawberry field prevents post-harvest pathogenic growth of fruits compared with control samples showing visible fungal presence at 17 days post-harvest (Fig. S3).

\section{DISCUSSION}

Plant extracts are beneficial alternatives for fungicides in control of phytopathogenic fungi due to the presence of bioactive chemicals such as flavonoids, phenols, tannins, and alkaloids. These secondary metabolites are more adaptable, associated with fewer environmental consequences compared to chemical pesticides, and are more acceptable to consumers. Bioactive compounds are part of an innate response elicited by most living organism, and are produced ubiquitously in plant roots, seeds, flowers, stems, and leaves, highlighting their physiological importance. Garlic is a well-known plant with anti-microbial activity. Wilson et al, (1997) reported that in the laboratory test of effects of 345 plant extracts on Botrytis cinerea, the garlic extract had an amazing inhibition reaction. The bioactive ingredients of VEG'LYS (https://phytoauxilium.com/) are proprietary; however, previous research on Allium-based compounds indicated that the thiosulphinate allicin and its derivatives account for the antibacterial activity of garlic (Hughes et al. 1991). Allicin acts by disrupting the sulfhydryl groups of proteins and the pools of other thiol stress constituents, such as glutathione (Miron et al. 2000; Müller et al. 2016). Based on the universality of the target sites of allicin, it is predicted that the activity of VEG'LYS would be durable, with no anticipated development of microbial resistance.

To determine the antimicrobial properties of VEG'LYS on the growth of plant pathogenic microorganisms such as fungi, oomycetes, and bacteria, in vitro, curative and preventive applications were tested. 


\section{In vitro Inhibition Assays}

The inhibitory activity of VEG'LYS was initially evaluated by determining the concentration needed to inhibit microbial colony growth by $100 \%$ (IC100) on agar medium. Both $C$. gloeosporioides and P. cactorum had an IC100 value of $0.01 \%$. This result is consistent with those of Okubara et al. (2017) who has shown that the inhibitory activity of VEG'LYS on various fungi and oomycetes had an IC100 value of $0.01 \%$ such as for Alternaria dauci and Botrytis cinerea. Reduction in growth rates of a group of soil borne fungal pathogens of cereals was observed at sub inhibitory concentrations of VEG'LYS. It was concluded that the Inhibition range may depend both on the pathogen and treatment (Okubara et al., 1997).

\section{The curative and preventive effects of VEG'LYS on carrot plants}

To evaluate the effects of VEG'LYS against pathogens on carrot plants, two different approaches were employed, namely curative and preventive methods. The results further confirmed the effect of VEG'LYS to prevent the growth of the necrotrophic grey mould fungus B. cinerea. Recently, several genes and signalling factors have been identified to play roles in pathogenesis, particularly in appressorium formation and penetration and these include the NOX complex, MAPK cascades, heterotrimetric G proteins, Histidine kinases and the Cyclic adenosine monophosphate (cAMP) signalling pathways (Castillo et al., 2017; Kumar et al. 2021, review article). In the present study differential expression levels of the $P R 10$ gene were analysed by RT-qPCR after VEG'LYS treatment on infected carrots. Both in treated and untreated plants, the expression level of $P R-10$ correlated with the magnitude of infection.

\section{Pre-harvest application of VEG'LYS in a strawberry field}

Strawberry fruits are consumed and beloved all over the world due to their taste, aroma, soft texture, nutritional and curative values. The fruit has high anthocyanin, phenol and vitamin $\mathrm{C}$ contents and these compounds are imperative for an effective free radical scavenging activity (Terefe et al., 2009). However, strawberry fruits are highly susceptible to fungal pathogens. In the past, the use of fungicides for their preservation and longer shelf life was common but nowadays WHO prevents the use of chemicals for preservation and warns about their effects on public health and the environment (Samadi et al., 2017). Strawberry contains 90 percent water, and the high levels of respiration make it vulnerable to microbial contamination and transpiration, which results in a short shelf life (Wright et al., 1997). Some studies suggested 
increasing strawberry shelf life by applying ascorbic acid, salicylic acid, radiations and various plant extracts (Boyraz and Ozcan, 2005). All these methods have their pros and cons. In this study, the effectiveness of VEG'LYS in extending the shelf life of strawberry fruits was further analysed. The results showed that even 17 days post-harvest, 75 percent of fruits treated with VEG'LYS were still not infected by fungi. Presence of pathogenic growth was confirmed by phenotyping in which there was a heavy infection detectable on fruits sprayed with sterilized water (the first row) with a massive loss of the bright red color, juicy texture and the sweetness of the fruits due to the presence of pathogen(s). This was in contrast to fruits treated with different concentrations ( 0.1 and $0.2 \%$ ) of VEG'LYS in which no pathogen presence could be ascertained but some had a slight loss of the bright red color and the succulence of the fruits. Most interestingly in fruits harvested from the row sprayed with $0.5 \%$ VEG'LYS, tissue integrity was maintained (there was no trace of pathogen growth, the bright red color, the juicy texture and the sweetness was intact as seen in the graphical result shown) and this concentration did not affect the taste and the sweetness of the fruits.

VEG'LYS inhibited the growth of B. cinerea and A. dauci on carrot plants, applied both curatively and preventively. The level of infection or the damage inflicted by the pathogens on the inoculated carrot plants was rated by phenotyping, which was supported by molecular analysis through qPCR. The data generated from molecular quantification of fungal growth in plant samples corroborated with the physical rating of infection levels. These results suggest that these plant extracts (i.e. VEG'LYS) have a prospective potential for plant protection and can be used in order to keep up with a constantly growing global demand for food supplies. 


\section{Legends of figures}

Fig.1 Inhibition by VEG'LYS of fungal growth under the lab condition. After 5dpi, the concentration at $0.05 \%$ completely inhibited the growth of Phytophthora cactorum. The concentration at $0.01 \%$ allowed a minimal pathogen growth (A and $\mathrm{B}$ ).

Fig. 2 Inhibition by VEG'LYS of fungal growth under the lab condition. After 5 dpi, the concentration at $0.05 \%$ completely inhibited the growth of Colletotrichum gloeosporioides. The VEG'LYS concentration at $0.01 \%$ allowed a moderate pathogen growth (A and B).

Fig. 3 Inhibition by VEG'LYS of bacterial growth under the lab condition. All the VEG'LYS concentrations tested $(0.01 \%$ and $0.02 \%)$ inhibited the growth of $X$. fragariae. Minimum LC should be determined as below $0.01 \%$. Bars represent standard deviation of three replicates and significant changes are marked: $*=\mathrm{p}<0.05 ; * *=\mathrm{P}<0.01 ; * * *=\mathrm{p}<0.001$ (Student's t test).

Fig. 4. Quantification of fungal DNA in carrot sprayed with fungal conidia.

Relative amount of DNA were quantified by qPCR. (A) Relative amount of DNA (Adgpd gene) of $A$. dauci in carrot plants normalized with carrot ubiquitin gene. (B) Relative amount of DNA ( $\beta$-tubulin gene) of $B$. cinerea in carrot plants normalized with carrot ubiquitin gene. Bars represent standard deviation of three replicates and significant changes are marked: $*=p<$ $0.05 ; * *=\mathrm{P}<0.01 ; * * *=\mathrm{p}<0.001$ (Student's t test). : $\mathrm{PR}=$ preventive; $\mathrm{CU}=$ curative; $\mathrm{CA}=$ Control non-treated

\section{Fig. 5 Quantification of $P R 10$ gene expression in carrot sprayed with fungal conidia.}

Relative expression of three different carrot $P R 10$ genes (syn. Dau c 1.01; Dau c 1.02 and Dau c 1.03) was quantified with qPCR and normalized with carrot ubiquitin. (A-C) Plants sprayed with $A$. dauci conidia. (D-F) Plants sprayed with B. cinerea conidia. Bars represent standard deviation of three replicates and significant changes are marked: $*=\mathrm{p}<0.05 ; * *=\mathrm{P}$ $<0.01 ; * * *=\mathrm{p}<0.001$ (Student's t test). $\mathrm{PR}=$ preventive; $\mathrm{CU}=$ curative; $\mathrm{CA}=$ Control nontreated 
Fig. S1 Carrot plants showing infection growth after being sprayed with $A$. dauci and $B$. cinerea conidia solution.

Carrot plants shown three weeks (A) and six weeks (B) post inoculation with $A$. dauci conidia.

(C) A. dauci conidial development in an infected carrot leaf (arrow) at 7 dpi. (D) Carrot plants heavily infected by $B$. cinerea at 7 dpi.

Fig. S2 The effect of VEG'LYS against B. cinerea and A. dauci on carrot plants.

(A) Control plants treated with distilled (mock)-water, (B) grey rot symptoms in carrot leaves caused by B. cinerea and A. dauci conidia (E) on carrot plants without VEG'LYS treatment. Preventive method indicating carrot plants were sprayed with VEG'LYS and subsequently followed by B. cinerea (C) and A. dauci conidia (F) solution exactly $48 \mathrm{~h}$ post inoculation. Curative method with carrot plants being sprayed with $B$. cinerea (D) andd A. dauci conidia (G) solution and subsequent treatment with VEG'LYS after $48 \mathrm{~h}$.

\section{Fig. S3 Experiments with strawberry fruits.}

(A) Strawberry plants growing under field condition. (B) Pre-harvest VEG'LYS application on a strawberry field prevented post-harvest pathogenic growth on treated strawberries vs. untreated plants at 17 days post-harvest (arrow). At a VEG'LYS concentration of $0.5 \%(\mathrm{v} / \mathrm{v})$ no infected fruits were found. $(C)$ the infections rate were calculated in percent.

\section{Acknowledgement}

We would like to thank Ute Micknass for cultivation of carrot plants, Udo Schnepp and Volker Weisel for VEG'LYS application in field experiments. We also thank Maximilian Reul (https://wetterauer-fruechtchen.de/) for providing the materials for field experiments.

\section{REFERENCES}

Amadioha, A.C. (2003) Evaluation of some plant leaf extracts against Colletotrichum lindemuthianum in cowpea. Acta Phytopathologica et Enthomologica Hungarica, 38:259-265. 
Bennett, B.C., (2007) Economic Botany-Plants as food. Department of Biological sciences and center for ethnobiology and Natural products, Florida International University, Miami, FL 33199 USA.

Boyraz, N., Ozcan, M. (2005) Antifungal effect of some spice hydrosols. Fitoterapia, 76; 661-665.

Burt, S. A., Reinders, R.D. (2003) Antibacterial activity of selected plant essential oils against Escherichia coli O157:H7. Letters in Applied Microbiology, 36; 162-167.

Carlos, E. S., Jesus, A. B.C., Guadalupe, RS., Carmen, OS. (2015) Biologically Active and Antimicrobial Peptides from Plants. Biomedical Research International. Volume Article ID 102129, http://dx.doi.org/10.1155/2015/102129.

Castillo, L., Plaza, V., Larrondo, L.F., Canessa, P. (2017) Recent advances in the study of the plant pathogenic Fungus Botrytis cinerea and its interaction with the Environment. Current Protein and Peptide Science, 18; 976-989.

Das, K., Tiwari, R.K., Shrivastava, D.K. (2010) Techniques for evaluation of medicinal plant products as antimicrobial agent: current methods and future trends. Journal of Medical Plant Research, 4; 104-111.

Dong. Y., Zhao, M., Zhao, T., Feng, M. Chen, H., Zhuang, M., Lin, L. (2014) Bioactive profiles, antioxidant activities, nitrite scavenging capacities and protective effects on $\mathrm{H}_{2} \mathrm{O}_{2}$-injured PC12 cells of Glycyrrhiza glabra L. leaf and root extracts. Molecules, 19(7): 9101-13. doi:10.3390/molecules19079101.

Gurjar, M.S., Ali, S., Akhtar, M., Singh, K.S. (2012) Efficacy of plant extracts in plant disease management. Agricultural Sciences, 3; 425-433.

Gutierrez, J., Rodriguez, G., Barry-Ryan, C., Bourke, P. (2008) Efficacy of plant essential oils against foodborne pathogens and spoilage bacteria associated with ready-to-eat vegetables: Antimicrobial and sensory screening. Journal of Food Protection, 71; 1846-1854.

Hassan, S.M., Byrd, J.A., Cartwright, A.L., Bailey, C.A. (2010) Hemolytic and antimicrobial activities differ among saponin-rich extracts from guar, quillaja, yucca, and soybean. Applied Biochemistry and Biotechnology, 162; 1008-1017.

Hughes BG, Lawson LD. Antimicrobial effects of Allium sativum L. (garlic), Allium ampeloprasum L. (elephant garlic), and Allium cepa L. (onion), garlic compounds and commercial garlic supplement products. Phytother. Res. 1991; 5:154-158.

Imani, J., Kumar, N., Sand, B., Kogel, K.H. (2013) VEG'LYS, a product from allium, has a strong potential for plant disease control. ADIVK Aktuell, 26th General Assembly of German in Vitro Culture Working Group (ADVIK). Lünen, Germany.

Koch, E. and Slusarenko, A. (1990) Arabidopsis is susceptible to infection by a Downy mildew fungus. The Plant Cell, 2; 437-445.

Kumar, J., Ramlal, A., Mallick, D., \& Mishra, V. (2021). An Overview of Some Biopesticides and Their Importance in Plant Protection for Commercial Acceptance. Plants (Basel, Switzerland), 10(6), 1185. https://doi.org/10.3390/plants10061185.

Kumar, J., Ramlal, A., Kumar, K., Rani, A., \& Mishra, V. (2021). Signaling Pathways and Downstream Effectors of Host Innate Immunity in Plants. International journal of molecular sciences, 22(16), 9022. https://doi.org/10.3390/ijms22169022.

Leontiev, R., Hohaus, N., Jacob, C. et al. (2018) A Comparison of the Antibacterial and Antifungal Activities of Thiosulfinate Analogues of Allicin. Sci Rep. 8; 6763. doi.org/10.1038/s41598-01825154-9.

Mbega, E.R., Mortensen, C.N., Mabagala, R.B., Wulff, E.G. (2012) The effect of plant extracts as seed treatments to control bacterial leaf spot of tomato in Tanzania. Journal of General Plant Pathology, $78 ; 277-286$. 
Miron, T., Rabinkov, A., Mirelman, D., Wilchek, M., Weiner, L. (2000) The mode of action of allicin: Its ready permeability through phospholipid membranes may contribute to its biological activity. Biochim. Biophys. Acta. 1463; 20-30.

Müller A, Eller J, Albrecht F, Prochnow P, Kuhlmann K, Bandow JE, Slusarenko AJ, Leichert LIO. (2016) Allicin induces thiol stress in bacteria through S-allylmercapto modification of protein cysteines. J. Biol. Chem. 291; 11477-11490.

Okubara, P., Kumar, N., Hohenwarter, L., Micknass, U., Kogel, K-H., Imani, J., Graham, D., Doty, S.L. (2017) Inhibition of fungal and bacterial plant pathogens by Veg'lys ${ }^{\circledR}$, an Allium-BASED antimicrobial formulation. Journal of Biology and Nature 8(2): 40-51

Okubara, P.A., Arroyo-Garcia, R., Shen, K.A., Mazier, M., Meyers, B.C., Ochoa, O.E., Kim, S., Yang, C.H., Michelmore, R.W. (1997) A transgenic mutant of Lactuca sativa (lettuce) with a T-DNA tightly linked to loss of downy mildew resistance. Molecular Plant-Microbe Interactions

Opara, E.U., Wokocha, R.C., (2008) Efficacy of some plant extracts on the in vitro and in vivo control of Xanthomonas campestris pv. vesicatoria. Agricultural Journal, 3:163-170.

Samadi, S., Ghasemnezhad, A., Imani, J. (2017) Extending shelf life of strawberry using some prestorage treatments. Acta Horticulturae, 1156; 643-65. doi:10.17660/ActaHortic.2017.1156.94

Samadi, S., Ghasemnezhad, A., Naz, S., Imani, J. (2015) An approved protocol for Cynara scolymus and Momordica charantia seed surface sterilization for pre-explant in-vitro culture using Allium extract. Journal of Biology and Nature, 4; 47-55.

Schmittgen, T,D., Livak, K,J. (2008) Analyzing real-time PCR data by the comparative $C_{\mathrm{T}}$ method

Shenge, K.C., Mabagala, R.B., Mortensen, C.N. (2007) Identification and characterization of strains of Xanthomonas campestris pv. vesicatoria from Tanzania by biological system and sensitivity to antibiotics. African Journal of Biotechnology, 6; 015-022.

Shirazi, M.H., Ranjbar, R., Eshraghi, S., Sadeghi, G., Jonaidi, N., Bazzaz, N., Izadi, M., Sadeghifard, N. (2007) An evaluation of antibacterial activity of Glycyrrhiza glabra extract on the growth of Salmonella, Shigella and ETEC E. coli. Journal of Biological Sciences, 7; 827-829.

Slusarenko, A.J., Patel, A., Portz, D. (2008) Control of plant diseases by natural products: Allicin from garlic as a case study. European Journal of Plant Pathology, 121; 313-322.

Srivasata, S., Singh, V.P., Kumar, R., Srivasata, M., Sinha, A., Simon, S. (2011) In vitro evaluation of Carbendazim 50\% WP, antagonists and botanicals against Fusarium oxysporum $\mathrm{f}$. sp. psidii associated with rhizosphere soil of guava. Asian Journal of Plant Pathology, 5; 46-53.

Terefe, N. S., Matihaies, K., Simons, L., Versteeg, C. (2009) Combined high pressure-mild temperature processing for optimal retention of physical and nutritional quality of strawberries. Innovative Food Science and Emerging Technologies, 10; 297-307.

Wilson, C. L., J. Solar, M., S. El Ghaouth and M. E. Wisniewski. (1997) Rapid Evaluation of Plant Extracts and Essential Oils for Antifungal Activity Against Botrytis cinerea. Plant Disease, 81(2); 204-210

Wright, K.P., Kader, A.A. (1997) Effect of slicing and controlled-atmosphere storage on the ascorbate content and quality of strawberries and persimmons. Postharvest Biology and Technology, 10; 3948 . 